\title{
Estudos Medievalistas do Norte Europeu e o Estado da Arte no Brasil
}

\author{
Estudios Medievalistas del Norte Europeo y el Estado del Arte en Brasil
}

Medievalists Estudies in the European North and the State of Art in Brazil

Amanda Basilio Santos ${ }^{1}$

\begin{abstract}
Resumo
Este artigo pretende abordar o estado da questão dos estudos medievais que se dedicam à análise histórica do norte europeu no período medieval, assim como discutir o aprofundamento do entendimento destas regiões através da ampliação das fontes utilizadas pelos historiadores. Faremos um breve apanhado do desenvolvimento da historiografia europeia neste sentido, assim como discutiremos a ampliação do interesse dos pesquisadores brasileiros por esta área em questão nos últimos anos, destacando a criação de núcleos de pesquisas direcionados ao estudo do norte da Europa na Idade Média, em especial o NEVE (Núcleo de Estudos Vikings e Escandinavos) e o NEIBRAM (Núcleo de Estudos Interdisciplinares das Ilhas Britânicas: Antiguidade e Medievo).
\end{abstract}

Palavras-Chave: Medievo, Historiografia, Estudos Medievais.

\section{Resumen}

Este artículo pretende abordar el estado de la cuestión de los estudios medievales que se dedican al análisis histórico del norte europeo en el período medieval, así como discutir la profundización del entendimiento de estas regiones a través de la ampliación de las fuentes utilizadas por los historiadores. Haremos un breve vistazo al desarrollo de la historiografía europea en este sentido, así como discutiremos la ampliación del interés de los investigadores brasileños por esta área en cuestión en los últimos años, destacando la creación de núcleos de investigaciones dirigidos al estudio del norte de Europa en la Edad Media, especialmente el NEVE (Núcleo de Estudios Vikings y Escandinavos) y el NEIBRAM (Núcleo de Estudios Interdisciplinarios de las Islas Británicas: Antigüedad y Medievo).

Palabras claves: Medievo, Historiografía, Estudios Medievales.

\begin{abstract}
This article intends to address the state of the studies of medieval researchs that are devoted to the historical analysis of northern Europe in the medieval period, as well as to discuss the deepening of the understanding of these regions through the enlargement of the sources used by the historians. We will take a brief look at the development of European historiography in this sense, as well as discussing the expansion of the interest of Brazilian researchers in this area in recent years, highlighting the creation of research centers directed to the study of Northern Europe in the Middle Ages, especially the NEVE (Núcleo de Estudos Vikings e Escandinavos) and NEIBRAM (Núcleo de Estudos Interdisciplinares das Ilhas Britânicas: Antiguidade e Medievo).
\end{abstract}

Keywords: Middle Ages, Historiography, Medieval Studies.

\footnotetext{
${ }^{1}$ Doutoranda em História (UFRGS); Mestra em História Medieval (UFPEL); Especialista em Artes (UFPEL); Mestranda em Memória Social e Patrimônio Cultural (UFPEL). Pelotas, Rio Grande do Sul, Brasil; amanda_hatsh@yahoo.com.br.
} 


\section{Medievalística brasileira: trajetória ascendente}

Embora Alain Guerreau tenha afirmado que os estudos medievais iriam se constituir no Brasil como uma ciência de europeus que ecoaria em obras de brasileiros, como o Modo de Produção Feudal de J. Pinsky (1982), que atribui aos europeus o exclusivismo sobre o longo período medieval, o panorama atual não podia ser mais diferente. Temos como divisor de águas a década de 1990, que Rust e Bastos, defendem como o período que definiu o "direito de cidadania histórica dos estudos medievais no Brasil" (BASTOS; RUST, 2009, p.164). A partir da ABREM (Associação Brasileira de Estudos Medievais), fundada em 22 de março de 1996, os brasileiros mostraram que não apenas podem pesquisar o período medieval, como o podem fazer com extrema qualidade. Através desta entidade civil sem fins lucrativos, foi possível organizar as pesquisas que são realizadas no Brasil, e elaborar eventos cujas temáticas sejam focalizadas na Idade Média. A ABREM hoje conta com entorno de 450 sócios regulares, e além da sua publicação acadêmica (Revista Signum) que é reconhecida internacionalmente e conta com publicações de pesquisadores medievalistas europeus, o que fomenta a troca na produção científica, ainda organiza eventos, promove cursos e palestras, sendo que o principal evento promovido é o Encontro Internacional de Estudos Medievais.

Com aportes conceituais da "História das Mentalidades" foi possível encontrar a conexão entre um passado distante e sua importância para a compreensão dos dias atuais, justificando-se seu estudo. Grandes nomes da pesquisa nacional como José Rivair Macedo e Igor Salomão Teixeira produzem obras inovadoras dentro da pesquisa medieval, demonstrando o quão errôneo é a premissa de que o período medieval não pertence aos estudiosos brasileiros.

Em seu princípio, as pesquisas em história medieval estiveram, no Brasil, intimamente dependentes das pesquisas, metodologias e conceituações, oriundas dos medievalistas franceses. Por um longo período, esta dependência esteve clara nas produções, escassas, que circulavam no nosso país. Esta dependência estava atrelada a algumas razões, porém, a primeira seria o acesso a bibliografia especializada, que se dava através das poucas traduções ou importações sobretudo de estudos franceses.

Pesquisas que se encontram nestes moldes supracitados podem serlocalizados no nascedouro do medievalismo brasileiro. Em 1934 há o primeiro curso superior a abordar a história medieval em seu currículo, na Universidade de São Paulo (USP). Por falta de uma formação específica para medievalistas, o primeiro a orientar pesquisas dirigidas à história medieval na USP, foi o classicista francês, especializado em história romana, Jean Gagé. 
A primeira tese de doutorado sobre história medieval no Brasil, será feita, quase dez anos depois da introdução do medievalismo nos quadros curriculares. Em 1942, o pesquisador Eurípedes Simões de Paulo, defendeu sua pesquisa sobre o comércio varegue em Kiev, tese feita sob a orientação de Jean Gagé.

Os estudos em História Medieval no Brasil encontram-se em ritmo ascendente, estão sendo criados novos grupos de pesquisa que aumentam a gama de contextos locais e temporalidades estudadas, assim como aumentam o número de pesquisas publicadas na área. Um tema de pesquisa que antes concentrava-se no Rio de Janeiro e em São Paulo agora é estudado em todas as regiões brasileiras, sendo que as produções tiveram seu aumento significativo entre as décadas de 80 e 90. (AMARAL, 2011).

Ao que se deve este crescimento? Não desejamos aqui dar uma resposta definitiva, mas apontar o quinhão devido aos bancos de dados online nesta trajetória. Durante muito tempo os medievalistas brasileiros encontravam-se com dificuldades para o estudo deste período pela simples dificuldade de acesso às fontes medievais e à bibliografia especializada. Apenas um grupo muito seleto tinha condições de acesso direto aos seus objetos de pesquisa que implicava em viagens e grandes encargos financeiros, além do mais, parte da documentação ainda podia encontrar-se inacessível por conta de procedimentos de conservação e restauro, além das taxas que podiam ser cobradas para o acesso. Quanto à bibliografia, dependia-se de uma quantidade ínfima de obras traduzidas para o português - em geral ligadas à produção medievalística francesa, o que limitava tanto as temáticas como a metodologia e teoria utilizada - (SILVA; SILVA, 2007) ou dos serviços de importação disponibilizado por algumas livrarias, que em geral implicavam em espera de alguns meses.

Atualmente, embora ainda dependamos das importações, há à disposição do pesquisador uma vasta bibliografia especializada na internet, seja de livros que já não possuem mais direitos autorais, permitindo sua digitalização e disponibilidade gratuita, assim como livros em formatos digitais pagos, que podem ser acessados imediatamente após o pagamento. As importações também se ampliaram, pois pode-se encomendar livros através de bibliotecas internacionais, sendo o acervo disponível muito mais vasto. Não apenas temos acesso a produção historiográfica mais variada, podendo adquirir pesquisas dos mais diversos países, como temos acesso mais rápido, podendo comprar títulos recém lançados, sem depender de importações que podem levar anos.

Para além da questão bibliográfica, temos as fontes. A internet fornece acesso a uma imensa gama de informações, o problema reside em saber o que utilizar e como utilizar na 
pesquisa historiográfica. As facilidades fornecidas por estes recursos não podem levar o pesquisador a um trabalho relapso e que pode por esta razão vir a ser desqualificado.

Temos também de ressaltar que a informática já vem sendo utilizada por historiadores há um longo período de tempo e as discussões sobre esta temática já vem sendo desenvolvidas desde a década de 1970, inclusive no Brasil (SILVA, 1998, p.168-169).

Mesmo com a popularização dos computadores pessoais que permitiu que mais pesquisadores utilizassem a informática em suas pesquisas, o uso em geral foi para trabalhar em fontes seriais, e na organização sistemática destas fontes. Para a criação de bancos de dados de fontes históricas, segundo Edson Armando Silva, em geral fixava-se em fontes que já apresentassem padrões que pudessem gerar entradas para os bancos de dados, como certidões de casamento, por exemplo. Porém com o declínio da história quantitativa também decai a popularidade dos bancos de dados digitais (SILVA, 1998, p.170).

Acima de tudo o pesquisador, embora hoje cercado de fontes digitais, tem que saber selecionar o que é passível de uso na pesquisa histórica, o que muitas vezes está diretamente relacionado com a apresentação interna dos sites que tem a sua disposição. Saber, portanto, analisar o conteúdo e a forma como este conteúdo apresentação nestes bancos de dados digitais torna-se tarefa primordial para que a pesquisa se efetue com sucesso.

Graças a estes esforços de democratização das fontes, surgiram possibilidades novas de estudos aos pesquisadores brasileiros interessados nos estudos de História Antiga e Medieval. Com novas ferramentas de pesquisa diversificou-se o interesse alusivo às áreas geográficas de pesquisa. Atualmente temos dois grupos de estudos no Brasil preocupados com as discussões referentes ao norte europeu durante o medievo. O mais conhecido atualmente é o NEVE² (Núcleo de Estudos Vikings e Escandinavos). Segundo a descrição do próprio grupo:

\footnotetext{
O grupo interinstitucional NEVE tem por principal objetivo o estudo e a divulgação da História e cultura da Escandinávia Medieval e em especial da Era Viking, por meio de reuniões, organização de eventos, publicações e divulgações em periódicos e internet. Conta com a colaboração de professores, pós-graduandos e graduandos de diversas universidades brasileiras, além de colaboradores estrangeiros. (Disponível em: <http://neve2012.blogspot.com.br/>, acessado pela última vez em 12 de setembro de 2015).
}

Este grupo foi formado em 2010 e tem como coordenador principal o historiador Johnni Langer, e é institucionalmente ligado à Universidade Federal da Paraíba (UFPB). Atualmente conta com cinco linhas de pesquisas e com vinte e sete membros entre

\footnotetext{
${ }^{2}$ Site oficial do NEVE: http://neve2012.blogspot.com.br/. E-mail de contato: neveufpb@yahoo.com.br.
} 
pesquisadores (dezesseis), estudantes (quatro), colaboradores estrangeiros (cinco) e técnicos (dois). O NEVE é um grupo bastante ativo e promove eventos anuais para promoção, divulgação e discussão de pesquisas relacionadas às suas linhas de pesquisa e à cultura nórdica europeia em geral. Além dos eventos mantém uma publicação de periodicidade semestral, intitulada Notícias Asgardianas, a qual é focada em publicação de estudos referentes à Escandinávia Medieval, em termo multidisciplinar, abarcando pesquisas de história, arqueologia, religiosidade, literatura, etc.

Seu coordenador, Johnni Langer, possui uma ampla produção historiográfica, com abrangência internacional. Em 2011 teve seu artigo Morte, Sacrificio Humano e Renascimento: Uma interpretação Iconográfica da Runestone Viking de Hammar I (LANGER, 2004), publicado no ano de 2004 pela revista Mirabilia, citado no estudo Der Tod des Todes (WEGENER, 2011), do pesquisador Dr. Bernhard Wegener, que foi publicado pela revista Zeitschrift für Spiritualität und Transzendentale Psychologie (V. 1, n²).

Um grupo mais recente que segue uma linha semelhante é o NEIBRAM ${ }^{3}$ (Núcleo de Estudos Interdisciplinares das Ilhas Britânicas: Antiguidade e Medievo). Segundo a descrição do grupo no CNPQ:

O NEIBRAM é um núcleo de estudos acadêmicos interinstitucionais de caráter interdisciplinar voltado às temáticas ligadas ao arquipélago das Ilhas Britânicas durante o período da Antiguidade e Idade Média. Ele abrange os campos da História, Arqueologia, Literatura, Antropologia, Arte, Linguística, Filosofia, entre outros. [...]. Sua principal proposta é de atender uma demanda cada vez maior no meio acadêmico brasileiro [...] por temas que extrapolem abordagens de pesquisa mais tradicionais, envolvendo as Ilhas Britânicas e sua relação com o Continente dentro do período proposto. (Disponível em: <http://dgp.cnpq.br/dgp/espelhogrupo/9640514370248566>, acessado pela última vez em 12 de setembro de 2015)

Este é um grupo ainda mais recente, sendo criado em 2014, e tem como coordenadores Renan Marques Birro e Elton Oliveira Souza de Medeiros e está ligado à Universidade Federal do Amapá (UNIFAP).

Atualmente possui sete linhas de pesquisa e vinte e um membros entre pesquisadores (dezesseis) e colaboradores (cinco).8 Possui também parceria com outros grupos de estudos e periódicos da Antiguidade e Medievo brasileiros como o Brathair (Grupo de Estudos Celtas e Germânicos) e o LATHIMM (Laboratório de Teoria e História da Imagem e Música Medievais) da Universidade de São Paulo, assim como possui parceria com universidades e grupo de estudos internacionais, como a University of Winchester. Este é um grupo ainda

\footnotetext{
${ }^{3}$ Site oficial do NEIBRAM: http://www.neibram.org/. E-mail de contato: neibram@infohistoria.org.
} 
recente, que está em momentos de adaptação e expansão, não possuindo ainda a abrangência conquistada pelo NEVE.

Embora estes grupos sejam novos e ainda pouco divulgados, são uma amostragem do crescimento do interesse de medievalistas e classicistas brasileiros pelo norte europeu. Além disso, são um importante indicador da ampliação geográfica dos estudos em história medieval no Brasil, que antes se concentravam em dois polos regionais: São Paulo e Rio de Janeiro.

As possibilidades de maior acesso às fontes e bibliografia especializada auxiliam este crescimento, assim como as escolhas de referenciais teóricos, que não exigem uma ligação direta com o passado estudado, como acontecia com o medievalismo no Brasil, que deveria estar ligado à Espanha ou a Portugal, por sermos hereditários diretos destas regiões. Hoje se possui uma visão mais democrática e menos bairrista nos estudos historiográficos, permitindo análise de locais antes não abordados. Percebemos também que estes grupos se encontram distantes dos centros tradicionais de estudos em Antiguidade e Medievo no Brasil, que tradicionalmente se localizam no Rio de Janeiro e em São Paulo, o que demonstra a grande expansão destas pesquisas no país.

\section{Considerações Finais}

Os estudos medievalistas no Brasil encontram-se em um período de franca expansão. Muito se deve à democratização do acesso às fontes por meio de bancos de dados digitais, facilitando e permitindo ao pesquisador brasileiro acesso aos seus objetos de pesquisa sem a necessidade de deslocamento físico. Como consequência, ou talvez em mão inversa, uma das causas, do alargamento deste campo de estudos, temos o surgimento de diversos grupos de pesquisas pelo nosso território nacional. Desta forma, o engajamento de pesquisadores, ainda no início de sua carreira científica, vem sendo ampliado, o que vem alimentando a produção em história medieval em um país onde antes se pensava ser algo improvável, se não, impossível.

\section{Referências}

ALMEIDA, A. C. L.; AMARAL, C. D. O. O Ocidente Medieval segundo a Historiografia Brasileira. Medievalista Online, v. 4, n. 4, p. 1-41, 2008.

AMARAL, R. O Medievalismo no Brasil. História Unisinos, 3, n. 15, Setembro/Dezembro 2011. 446-452.

BAKHTIN, M. A Cultura Popular na Idade Média e no Renascimento: o contexto de François Rabelais. São Paulo: Hucitec, 1987. 
BECKWITH, S. Christ's Body: Identity, Culture and Society in Late Medieval Writings. Nova York e Londres: Routledge, 1996.

BLOCH, M. A Sociedade Feudal. Lisboa: Edições 70, 1987.

BLOCH, M. Apologia da História ou o Ofício do Historiador. Rio de Janeiro: Zahar, 2001.

BRADLEY, I. Believing in Britain: The Spiritual Identity if Britishness. Londres: I. B.

Taurus, 2007.

COHEN, J. J. Cultural Diversity in the British Middle Ages: Archipelago, Island, England. Nova York: Palgrave McMilan, 2008.

COLLEY, L. Britons: Forging the Nation, 1701-1837. 2ª ed. Londres: Pimlico, 2005.

CONDE-SILVESTRE, J. C.; CALLE-MARTÍN, J. (Eds.). Approaches to Middle English: Variation, Contact and Change. Nova York e Oxford: Peter Lang, 2015.

DIAS, A. F. Dos estudos culturais ao novo conceito de Identidade. Gepiadde, Itabaiana, v. 9, n. 5, 2011.

FALCON, F. História e Poder. In: CARDOSO, C. F.; VAINFAS, R. Domínios da História: ensaios de teoria e metodologia. Rio de Janeiro: Campus, 1997. p. 97-138.

HALL, S. Da diáspora: identidades e mediações culturais. Belo Horizonte: UFMG, 2003. KHANMOHAMADI, S. A. In Light of Another's Word: European Ethnography in the Middle Ages. Philadelphia: PENN, 2014.

MACEDO, J. R. Os estudos medievais no Brasil: catálogo de teses e dissertações. Porto Alegre: EDUFRGS, 2003.

NEIL, D. G. The Masculine Self in Late Medieval England. Chicago: Chicago University Press, 2008.

NÚCLEO de Estudos Vikings e Escandinavos, 2012. Disponivel em:

<http://neve2012.blogspot.com.br/>. Acesso em: 12 setembro 2015.

REIS, J. C. Nouvelle histoire e tempo histórico: a contribuição de Fevre, Bloch e Braudel. São Paulo: Ática, 1994.

RIX, R. W. The Barbarian North in the Medieval Imagination. Nova York: Routledge, 2015.

RUST, L. D.; BASTOS, M. J. D. M. Translatio Studii: A História Medieval no Brasil. Signum, São Paulo, v. 10, p. 163-188, 2009.

SILVA, E. A. Bancos de Dados e Pesquisa Qualitativa em História: Reflexões acerca de uma experiência. Revista de História Regional, v. 3, n. 2, p. 167-176, 1998. 
SILVA, L. R. D.; SILVA, A. C. L. F. Os Estudos Medievais no Brasil e a Internet: uma análise do uso dos recursos virtuais na produção medievalista (1995 a 2006). História, imagem e narrativas, Ano 2, n. 4, 2007. 134-147.

SILVA, T. T. Identidade e diferença: a perspectiva dos estudos culturais. Petrópolis: Vozes, 2000 .

SMITH, A. Set in the Silver Sea: English Nacional Identity and European Integration.

Workshop: National Identity and Euroscepticism: A Comparison Between France and the United Kingdom., Oxford, p. 1-14, 2005. 